\title{
Editorial
}

\section{The need for vitamin D assay standardisation in research}

In our recent vitamin D issue (Volume 23 - Issue 7 - May 2020), we have published eleven research papers, one short commentary, a letter to the editor, two invited commentaries, one commentary and an editorial on various aspects of vitamin D as it relates to public health, indicating the level of interest in this topic.

The papers included identified potential associations between low vitamin $\mathrm{D}$ and a range of health outcomes, adding to many existing publications on the potential benefits of vitamin $\mathrm{D}$ across a range of conditions, for example a recent umbrella review ${ }^{(1)}$. The possibility of vitamin D being beneficial against COVID 19 has even been raised but is only hypothetical at present ${ }^{(2)}$. However, as described in the editorial, there is a lack of agreement between countries and other non-government medical societies and organisations as to the serum concentration of total 25 hydroxyvitamin D $(25(\mathrm{OH}) \mathrm{D})$ that reflects inadequacy, and whether concentrations can be further classified as insufficient, sufficient or toxic ${ }^{(3)}$.

As explained in great detail by Sempos and Brinkley ${ }^{(3)}$, a major contributor to the lack of consensus around adequate serum levels of $25(\mathrm{OH}) \mathrm{D}$ is the variability in the assays used to measure it. To overcome this and get consensus in studies looking at vitamin D and different outcomes, as well as cut-offs for adequate and inadequate levels of serum 25(OH)D, Sempos and Brinkley ${ }^{(3)}$ are calling for standardisation of vitamin D assays globally. As an example of the difference this can make, a large study across fourteen populations in Europe applied Vitamin D Standardization Program protocols to existing data to re-estimate the prevalence of low $25(\mathrm{OH}) \mathrm{D}^{(4)}$. In a population representative sample of adults from Germany, the prevalence of deficiency, defined as $<30 \mathrm{nmol} / \mathrm{l}$, decreased from 25.9 to $15.2 \%$; while in Ireland, it increased from $6 \cdot 6$ to $12 \cdot 3 \%$. This was equivalent to making $10 \cdot 4$ million Germans no longer deficient and finding an extra 267000 deficient adults in Ireland. Elsewhere, Jakab et $\mathrm{al}^{(5)}$ retrospectively standardised the results for 206 samples in the HunMen cohort. The mean total $25(\mathrm{OH}) \mathrm{D}$ changed from 53 to $62 \mathrm{nmol} / \mathrm{L}$, and the prevalence of hypovitaminosis D ( $<75 \mathrm{nmol} / \mathrm{L}$ ) decreased from 84 to $72 \%$.

To ensure that articles published in PHN can contribute to consensus, and where appropriate to defining adequate and other levels of $25(\mathrm{OH}) \mathrm{D}$, we are proposing to introduce a requirement that all papers published in Public Health Nutrition use standardised 25(OH)D levels that are fit for purpose. The Vitamin D Standardization Program has developed two options for retrospective standardisation of existing measures ${ }^{(6)}$. This would not apply to papers that have already been submitted and are undergoing review but will be taken into account for new submissions starting in 2021. The change will also be reflected in updated Instructions to Authors.

\section{Acknowledgements}

Acknowledgements: The author thanks Christopher Sempos for advice. Financial support: None. Conflict of interest: None. Authorship: A.M.H. performed all tasks. Etbics of buman subject participation: Not applicable, no research involving humans was conducted.

Allison M Hodge $\mathrm{M}^{1,2}$ (D)

${ }^{1}$ Cancer Epidemiology Division, Cancer Council Victoria, 615 St Kilda Rd, Melbourne, VIC, Australia

${ }^{2}$ Centre for Epidemiology and Biostatistics, Melbourne School of Population and Global Health, University of Melbourne, Parkville, VIC, Australia Email allison.hodge@cancervic.org.au

\section{References}

1. Maretzke F, Bechthold A, Egert S et al. (2020) Role of vitamin D in preventing and treating selected extraskeletal diseases-an umbrella review. Nutrients 12. doi: 10.3390/nu12040969.

2. Grant WB, Lahore H, McDonnell SL et al. (2020) Evidence that vitamin D supplementation could reduce risk of influenza and COVID-19 infections and deaths. Nutrients 12. doi: 10.3390/ nu12040988.

3. Sempos CT \& Binkley N (2020) 25 -Hydroxyvitamin D assay standardisation and vitamin D guidelines paralysis. Public Health Nutr 231, 153-1164.

4. Cashman KD, Dowling KG, Skrabakova Z et al. (2016) Vitamin D deficiency in Europe: pandemic? Am J Clin Nutr 1, 033-1044.

5. Jakab E, Kalina E, Petho Z et al. (2017) Standardizing 25-hydroxyvitamin $D$ data from the HunMen cohort. Osteoporos Int 281, 653-1657.

6. Sempos CT, Durazo-Arvizu RA \& Carter GD (2017) Cost effective measures to standardize serum $25(\mathrm{OH}) \mathrm{D}$ values from completed studies. Osteoporos Int 281, 503-1505. 